\title{
PELOS OLHOS DE CLÁUDIA ANDUJAR: NECROPOLÍTICA E COETANEIDADE ENTRE OS YANOMAMI
}

The "Marcados" and "Sonhos Yanomami" photographic series by Cláudia Andujar: necropolitic and different temporalities in the Yanomami cosmology

\author{
Ivânia dos Santos Neves (UFPA) \\ Ana Shirley Penaforte Cardoso (UFPA)
}

\begin{abstract}
RESUMO: O tempo e as imagens não podem ser concebidos como homogeneidades, mas sim como construções históricas, imbricados em tramas culturais, envolvidos em relações de poder, intensamente administrados. Neste artigo, vamos analisar duas séries de imagens produzidas pela fotógrafa Cláudia Andujar sobre a história e a cultura do povo indígena Yanomami. Na primeira parte, dedicamos uma atenção especial às quatro possíveis formas de relação da imagem fotográfica com o tempo. Em seguida, para compreender as condições de emergências históricas da série fotográfica "Marcados", tomamos como referencial teórico-metodológico as discussões sobre biopolítica e necropolítica. Por fim, fizemos uma discussão sobre as diferentes temporalidades apresentadas nas fotografias da série "Sonhos Yanomami".
\end{abstract}

PALAVRAS-CHAVE: Fotografia; Biopolítica; Antropologia visual; Amazônia.

ABSTRACT: Time and images cannot be conceived as something homogenous, but as historical constructions, embedded in cultural frames, involved in relations of power. In this article, we will examine two series produced by photographer Cláudia Andujar about the history and culture of the indigenous Yanomami people. In the first part, we devote special attention to four possible forms of relating the photographic image with time. Then, in order to understand the conditions of production of the photographic series "Marcados", we base our analysis on theoretical-methodological discussions about biopolitics and necropolitcs. Finally, we present a discussion about the different temporalities offered in photographs from the series "Yanomami Dreams".

KEYWORDS: Photography; Biopolitics; Visual anthropology; Amazon. 


\section{Introdução}

Todas as manhãs se erguiam sete sois sobre a planície de Inharrime. Nesses tempos, o firmamento era bem maior e nele cabiam todos os astros, os vivos e os que morreram. Nua, como havia dormido, a nossa mãe saía de casa com uma peneira na mão. Ia escolher o melhor dos sois. Com a peneira recolhia as restantes seis estrelas e trazia-as para a aldeia. Enterrava-as junto à termiteira, por trás da nossa casa. Aquele era o nosso cemitério de criaturas celestiais. Por este patrimônio, nós não éramos pobres.

Mia Couto

Os processos de subjetivação a que foram expostos os povos indígenas, desde o início da colonização brasileira, sempre os fizeram caber dentro de uma generalização, como se existisse apenas uma sociedade e uma única cultura, sem perspectiva histórica. Num sentido oposto, os trabalhos da fotógrafa Cláudia Andujar procuram, há mais de 40 anos, materializar o cotidiano e as singularidades do povo Yanomami, quer seja denunciando a política de morte que lhes foi imposta a partir do contato sistemático, ou procurando traduzir em imagens seus rituais sagrados, profundamente ligados à relação desse povo com espíritos da natureza.

Atravessando as tênues fronteiras entre o fotojornalismo, a fotografia documental e a fotografia artística, Andujar inscreveu o corpo Yanomami na mídia nacional e internacional. Nas paredes das galerias e museus, assim como nas páginas de revistas, as imagens que produziu visibilizam diferentes temporalidades, brincam com a dicotomia ficção e realidade e dissolvem os limites entre o sensível e o inteligível. Seu fraturado lugar de enunciação nos convida a pensar a linguagem fotográfica em toda sua complexidade.

As reflexões acerca da imagem fotográfica vão além de suas possibilidades de uso técnicos, estéticos e visuais. A análise da imagem e de sua potencialidade de circulação, de forma geral, delineia gestos de leitura, estabelece verdades, traduz relações de poder, evidencia as singularidades da história. A fotografia também pode ser pensada como uma materialidade para a construção de uma memória social institucionalizada, que estabiliza discursos generalizantes sobres os povos indígenas, circula em documentos oficiais, está presente nos museus, nos livros didáticos. Por outro lado, de forma mais particularizada, ela também pode revelar imagens silenciadas, interditadas e mostrar uma versão mais singular da história. Para Novaes (2005, p. 110): 
A fotografia explicita esta mistura feliz de informação, acaso, estética e intenção. Ela fala, claramente, neste sentido não apenas sobre o objeto, mas, de modo igualmente evidente, sobre a cultura e estilos de vida de quem opera a câmera. Se as imagens produzidas são eloquentes, podem igualmente ser eloquentes os silêncios e ausências de determinadas imagens.

Entendemos, portanto, as fotografias como ativadores de memória, como linguagem que dialoga com a percepção do que se viveu ou que ainda poderá ser vivido. Neste sentido, as imagens produzidas por Cláudia Andujar não são apenas registros neutros e sim enunciados enredados em teias de memórias. Elas foram produzidas a partir das emergências da história dos Yanomami, mas também traduziram sua trajetória pessoal.

Neste artigo, vamos analisar duas séries fotográficas realizadas por Cláudia Andujar entre os Yanomami, elaboradas ao longo de sua carreira, "Marcados" e "Sonhos Yanomami", considerando os aspectos políticos que envolvem o corpo Yanomami e as possibilidades técnicas de tradução da cosmologia desta sociedade para a linguagem fotográfica. Para isso, propomos uma discussão inicial sobre as implicações discursivas do tempo na fotografia.

\section{Sobre tempo e fotografia na obra de Cláudia Andujar}

Recai sobre o silenciamento de temporalidades diferentes do tempo cronológico cristão uma das mais produtivas críticas imputadas às ciências humanas ocidentais. Como adverte Reinhardt (2014, p. 332): “a temporalidade é, além de um horizonte no qual se desenrola a busca coletiva pela compreensão, um dos objetos postos em disputa pelas lutas históricas". O apagamento das línguas, das iconografias e das práticas religiosas orquestrado pelo sistema colonial na América desconsiderou os diferentes tempos em que se organizavam as cosmologias locais. Nesta mesma tendência, também a linguística, a antropologia e as primeiras etnografias ignoraram em seus registros os aspectos políticos destes tempos tanto em relação às identidades locais, quanto à importância do tempo do outro para os processos de interação entre sujeitos de culturas diferentes. (FABIAN, 2013)

Nossa percepção acadêmica ocidental procurou esquadrinhar o tempo na palavra escrita, mas também na palavra falada das línguas europeias. A ordem cronológica, didaticamente dividida em quatro grandes épocas produziu, entre outras 
invenções, o discurso de que o tempo, tomado como uma singularidade, divide-se em passado, presente e futuro. Mas, longe de serem classificações neutras, as questões políticas que envolvem estes tempos verbais já fundamentaram, por exemplo, o evolucionismo cultural, que pressupunha ser possível conhecer o passado da humanidade apenas investigando os povos mais "primitivos".

A reação a este tempo passado racializado dos evolucionistas será um dos principais fundamentos das perspectivas a-históricas propostas pelas escolas funcionalista-britânica e estruturalista-francesa para compreender as diferenças culturais, mas é preciso notar que são também duas correntes de pensamento descomprometidas com o tempo do outro e negam a existência simultânea de múltiplas temporalidades: "A negação da coetaneidade torna-se intensificada, à medida que o distanciamento do tempo passa de um interesse explícito, para um pressuposto teórico implícito." (FABIAN, 2013, p. 73)

Mais especificamente em relação à fotografia para analisar estas diferentes temporalidades culturais, vamos associá-la às tecnologias de poder, mas não podemos desconsiderar os processos químicos, físicos e digitais que envolvem os registros fotográficos. Para Entler (2007), podemos estabelecer quatros parâmetros nesta relação:

a) O tempo inscrito na imagem - Um dos primeiros desafios da fotografia foi a redução do tempo de exposição do diafragma e sua impressão em uma superfície sólida. Durante muito tempo também, a reprodução de várias cópias de uma única fotografia foi a causa de frenesi entre os pesquisadores. O ideal era se chegar a uma imagem nítida, sem ruído, a representação mais verossímil possível do real. Nesta perspectiva, o borrão era considerado um defeito. $\mathrm{O}$ instantâneo representou uma conquista técnica, que materializa o desejo do real.

O último quarto do século XIX marca a emergência da noção de instantâneo, que não é simplesmente uma questão (técnica) de curto tempo de exposição e sim toda uma lógica, para não dizer uma filosofia da relação com o real (com o espaço, o tempo, o corpo, o mundo), que demorou quase três séculos para se construir e que vai depois reinar de maneira maciça na ideologia fotográfica a ponto de quase se identificar com a própria ideia de fotografia (como seu próprio ser) e consequentemente eliminar todas as formas que esta pode ter. (DUBOIS, 2010, p. 203)

b) O tempo denegado pela imagem - A capacidade técnica das câmeras evoluiu no sentido de conseguir capturar um fragmento do tempo corrente, que pressupõe a 
paralização de um corte temporal. $O$ instante fixado pela fotografia congela $o$ movimento, mas não consegue parar o tempo.

Imaginemos um salto congelado... Bem, se chamamos aquilo de "salto" é porque já deciframos o movimento. O que vemos é apenas alguém parado no ar, mas não entendemos que aquele homem esteja efetivamente parado. Compreendemos o salto, um movimento que inclui aquela etapa registrada, mas também outras anteriores e posteriores. O modo abrupto e forçoso como o tempo é retirado de cena é uma ação que se trai, pois tal denegação acaba por constituir, ela mesma, uma forma de representação daquilo que foi ocultado. (ENTLER, 2007, p. 36)

c) O tempo decomposto pela imagem - Esta perspectiva se aproxima bastante da linguagem cinematográfica, pois compreende a série fotográfica como um processo de apreensão da vida em movimento.

A estruturação sequencial de imagens está também na base de quase todas as experiências com narrativas visuais, incluindo aí o cinema e os quadrinhos. Aparece também numa longa tradição da pintura: as inscrições nas pirâmides que mostram a passagem dos faraós para uma vida após a morte, as cerâmicas gregas que contam feitos heroicos, as iluminuras medievais que relatam passagens bíblicas, além de dípticos e trípticos que podem também assumir uma forma narrativa. (ENTLER, 2007, p. 37)

Ainda em relação a esta perspectiva, se tomarmos como exemplo a série "Marcados", de Cláudia Andujar, faz diferença se observamos apenas uma única fotografia, ou o conjunto delas que, sem dúvida, provoca bem mais impacto. Uma foto sozinha produz diferentes sentidos tanto para quem a elabora, para o interlocutor e para quem é representado na imagem. Uma série fotográfica proporciona outros sentidos, que se diferenciam e se redimensionam ao longo da história.

d) Os tempos do olhar - As fotografias são enunciados inscritos em redes de memórias, imbricadas com suas condições de possibilidades históricas. Elas estabelecem processos de interação, demarcam o lugar e o olhar de quem as produziu. Diante do olhar de quem as observa podem ganhar diferentes interpretações. Por que surgiram determinadas imagens e não outras? Por que tantas fotografias foram esquecidas e apenas algumas ganharam notoriedade? Os dispositivos técnicos utilizados para a geração de uma imagem fotográfica, assim como todo o processo que as envolve estão inseridos em ordens discursivas.

Jamais se deverá esquecer na análise, sob a pena de ser enganado por essa epifania da referência absolutizante, que a jusante e a montante 
desse momento da inscrição 'natural' do mundo na superfície sensível (o momento da transferência automática de aparência), que, de ambos os lados, há gestos e processos, totalmente 'culturais', que dependem por inteiro de escolhas e decisões humanas, tanto individuais quanto sociais (DUBOIS, 2010, p. 85)

Nesta recente, mas bastante complexa história da fotografia, os caminhos percorridos entre tempo e fotografia são bem diversos. A obra de Cláudia Andujar nos coloca diante de uma epistemologia da imagem, que consegue não só transitar por diferentes temporalidades, mas também se fundir com elas. Para Tacca (2011, p. 217):

Suas fotografias nos permitem experimentar o invisível, em que a luz fotográfica encontra a luz cintilante dos espíritos. Os feiticeiros evocam o sobrenatural, ao passo que a fotógrafa evoca a nova magia da imagem técnica anunciada por Vilém Flusser. O referente não é aderido à imagem fotográfica pelo fato de ser uma construção simbólica; perde sua carga mítica original descontextualizando o evento religioso, para transformar-se em outra magia, uma magia contemporânea que não se propõe a modificar o mundo e sim nossos conceitos sobre ele.

A produção de Cláudia Andujar nos ajuda a pensar sobre a fotografia como uma narrativa visual, que nasceu das experiências com os Yanomami, mas que se singularizou em suas lentes. A realidade tecida cotidianamente, seja numa pequena aldeia africana, numa grande metrópole europeia, ou na Terra Indígena Yanomami pode se traduzir em várias versões, sempre implicadas com as condições de possibilidades históricas dos sujeitos que a produziram.

\section{A série "Marcados": necropolítica e fragmentos de uma teoria do sujeito Yanomami}

Me interesso muito pela questão da justiça e das minorias que estão tentando se afirmar no mundo, mas se deparam sempre com um dominador que procura apará-las. Mas existe também um outro lado, que é a estética, o equilíbrio, presente nas minhas imagens. Nem sempre o lado social pode se juntar ao lado estético. Eu sofro por isso. Quando consigo juntar as duas coisas, me sinto aliviada.

Cláudia Andujar

Em 1971, como fotojornalista da revista Realidade, Cláudia Andujar participou de uma reportagem especial sobre a Amazônia e pela primeira vez encontrou os Yanomami[1], em Maturacá, no estado do Amazonas. A maior parte de seu trabalho é 


\section{PELOS OLHOS DE CLÁUDIA ANDUJAR: NECROPOLÍTICA E COETANEIDADE ENTRE OS YANOMAMI}

dedicada a este povo indígena e sua longa experiência entre eles é o fio condutor de sua vida e de sua trajetória como fotógrafa.

A Terra Indígena Yanomami localiza-se ao norte da América do Sul entre dois países, Brasil e Venezuela, na floresta amazônica. No território brasileiro, situa-se nos estados de Roraima e do Amazonas. Segundo o último censo do IBGE (2010), há uma população estimada em pouco mais de vinte e cinco mil indígenas na parte brasileira. Em nosso país, em função de políticas públicas do governo federal, a partir de 1970, esta região sofreu bastante interferência em decorrência da construção da estrada Perimetral Norte, através do Plano de Integração Nacional (PIN). Este momento marca o início do contato sistemático deste povo com os não indígenas.

A história dos povos indígenas apresenta uma estatística trágica em relação aos primeiros contatos e, se por um lado o enfrentamento bélico foi determinante na imposição da colonização, sem dúvida, os problemas de saúde, em algumas situações responsáveis pela dizimação de sociedades inteiras, constituem um aspecto dramático deste processo. A investida dos governos militares na região em que viviam os Yanomami promoveu também a expansão da exploração garimpeira de jazidas minerais e estes acontecimentos produziram entre eles um choque epidemiológico, com alarmantes perdas demográficas e uma profunda degradação sanitária.

Quando Cláudia Andujar conheceu os Yanomami, dois fatores foram decisivos para que fosse viver com eles: o fascínio pela cosmologia Yanomami e a preocupação com as trágicas consequências do contato que estavam começando a sofrer. Decidiu então largar o fotojornalismo e experimentar novas linguagens fotográficas e uma nova forma de vida, passou a viver com eles em 1971 e só saiu de lá em 1978 quando, enquadrada na lei de Segurança Nacional pelo governo militar, foi obrigada pela FUNAI a se retirar da região.

No início de 1980, começou efetivamente um trabalho político de proteção aos direitos desta sociedade indígena e fundou a Comissão pela Criação do Parque Yanomami (doravante CCPY). Uma das primeiras iniciativas desta Comissão foi a realização de um programa de saúde, que previa uma campanha de vacinação, com o objetivo de prevenir as graves epidemias (sarampo, gripe e coqueluche) e o excessivo número de mortes entre eles.

Para facilitar o acompanhamento médico das pessoas atendidas nas ações do programa e minimizar as dificuldades de comunicação com os Yanomami, ainda com pouco contato com o português, foi necessária a criação de fichas de saúde para compor 
um cadastro com as informações particularizadas. Havia nas fichas uma fotografia em preto e branco (fig. 1), individual, em que os indígenas apareciam com pequenas placas numéricas em torno do pescoço. Como as condições epidemiológicas estavam bastante difíceis, a equipe do programa temia pela morte imediata dos indígenas registrados nas fotografias, o que de fato aconteceu com um número expressivo deles.
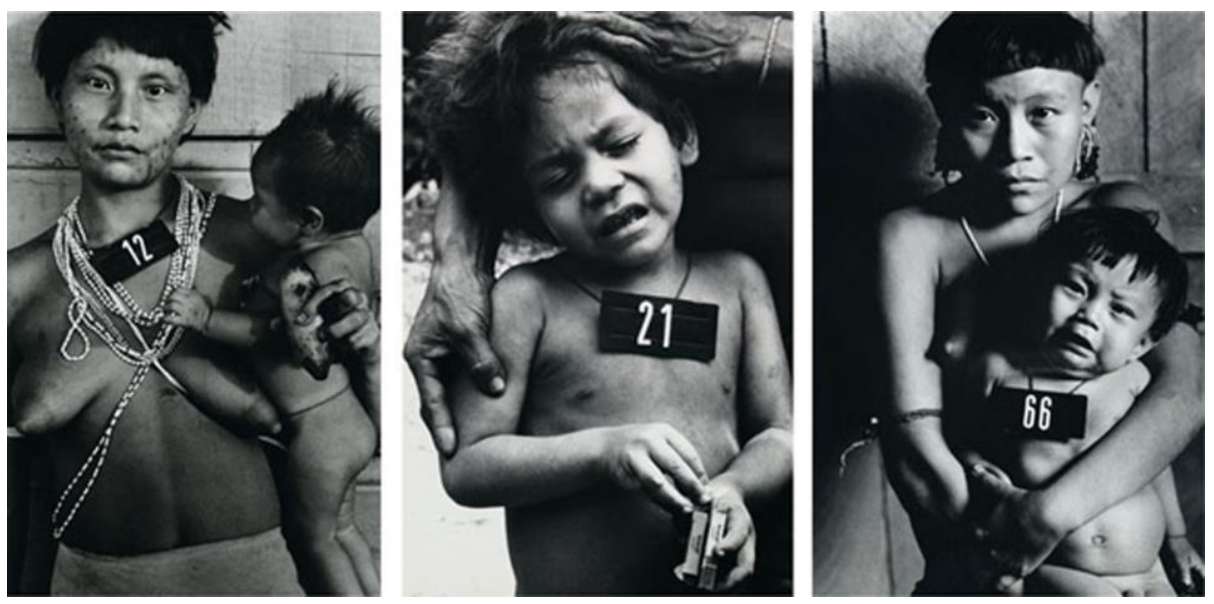

Figura 1. Marcados (ANDUJAR, 2009)

O conjunto destas imagens produziu um efeito que foi bem além do simples registro documental e afetou bastante a opinião pública nacional e internacional. Os retratos colocados lado a lado evidenciavam os problemas de saúde dos Yanomami. Assim nasceu a série fotográfica "Marcados", cujas imagens constituíram em grande medida a base estética e conceitual de Cláudia Andujar. O trabalho da artista ajuda a inscrever a condição social do povo Yanomami naquele momento e desta maneira, estas fotografias podem ser vistas como narrativas reconstrutoras de história, conforme diz Novaes:

Imagens, tais como textos, são artefatos culturais. É neste sentido que a produção e análise de registros fotográficos, fílmicos e videográficos podem permitir a reconstrução da história cultural de grupos sociais, bem como um melhor entendimento de processos de mudanças, dos impactos das frentes econômicas e da dinâmica das relações interétnicas. (2005, p. 110)

As epidemias trazidas pelos não indígenas se materializavam violentamente no corpo Yanomami. Diante destas fotografias em preto e branco, com corpos doentes e frágeis, identificados por números, com muita facilidade retomamos uma memória das imagens dos campos de concentração nazistas. É quase imperativo enredá-las num processo de intericonicidade (COURTINE, 2011). 
A experiência da morte coletiva de milhares de Yanomami dialogou profundamente com a memória de infância da fotógrafa. Cláudia Andujar nasceu na Suíça, em uma família judia, às vésperas da Segunda Grande Guerra. Perdeu toda sua família paterna nos horrores do holocausto. Precisou se exilar da Europa para sobreviver, a princípio nos Estados Unidos e posteriormente no Brasil. Os números das placas dos Yanomami, das roupas ou da pele dos judeus, por diferentes razões, em cosmologias e histórias bem diferentes, imbricavam-se com a morte do corpo.

A condição em que os Yanomami aparecem na série "Marcados", consequência direta de ações da última ditadura militar brasileira, assim como as fotografias das vítimas dos campos de concentração da Segunda Grande Guerra guardam profundas diferenças, sobretudo em relação às suas emergências históricas. No campo das regularidades, podemos identificar dois processos que impõem uma política de morte do corpo muito semelhante e não se trata apenas da morte do indivíduo investido em práticas de subjetivação, mas sim da morte coletiva.

Para analisar as políticas impostas aos corpos Yanomami, tomamos como referência inicial as formulações de Michel Foucault (2005b) sobre biopolítica. A princípio, ele nos apresenta o corpo dócil, útil e disciplinado a serviço dos modos de produção do sistema capitalista, portanto, um corpo que precisa estar vivo. Depois, atento à crise econômica internacional dos anos de 1960 e 1970, que vai dispensar grandes massas de trabalhadores, Foucault $(2007,2012)$ passa a se interessar pela segurança das populações, pela governamentalidade. Nesta perspectiva, o corpo passa a ser coletivo, não mais submetido à disciplina, mas sim a sofisticados processos de controle da vida, que inclui estabelecer as regras sobre vida e morte.

Os corpos Yanomami representavam um obstáculo à integração da Amazônia ao centro-sul do país, não se inscreviam como úteis, tampouco interessava aos governos militares lhes garantir alguma forma de segurança. Na condição em que viviam, nem a periferia do capitalismo lhes poderia ser reservada, eram a negação do progresso. Bastante embaladas pelas questões raciais impostas pela colonização europeia, as políticas empreendidas pelos militares não reconheciam as formas jurídicas, nem respeitaram os direitos humanos, afinal, estavam na posição de decidir quem era humano.

Para entender melhor esta situação, vamos tomar um conceito que parte da biopolítica mas que, de certa forma, inverte e potencializa sua lógica, a necropolítica, formulado por Achille Mbembe (2006). Para o autor, existem políticas fundamentadas 
na destruição material de corpos humanos e populações, portanto, em vez de pensar nas políticas de corpos vivos, vai se debruçar sobre a instituição dos corpos mortos. Estes processos são frequentes em antigas ou atuais colônias europeias e em sua dinâmica não existe o inimigo a ser destruído pela guerra, pois os "selvagens" não podem ser elevados a categoria de inimigos, uma vez que não são considerados humanos. Não existe, portanto, uma soberania a ser destruída, como nota Mbembe:

A ocupação colonial da modernidade tardia é uma cadeia de múltiplos poderes: disciplinar, "biopolítico" e "necropolítico". A combinação destes poderes permite o domínio absoluto sobre os habitantes do território conquistado. (2006, p. 53)[2].

As epidemias entre os Yanomami, denunciadas pelas fotografias de Cláudia Andujar atestam a administração de um necropoder, são consequências imediatas do plano de integração da região e da falta de proteção à saúde desta sociedade. Se nos campos de concentração nazistas os judeus eram sumariamente assassinados em nome de uma guerra que em 1945 chegou ao fim, nas fronteiras da Terra Yanomami não havia um momento de guerra factível de se alternar com a paz, não houve matadores visíveis, mas o próprio governo brasileiro criou as condições para deixá-los morrer.

Há uma característica da cosmologia Yanomami bastante peculiar que se evidenciou durante a realização do programa de saúde da CCPY: em suas práticas de interação tradicionais, eles não têm nomes próprios. Para as racionalidades ocidentais é muito difícil conceber uma ordem social com pessoas anônimas. Nas fronteiras culturais, sem os nomes próprios, os registros fotográficos e os números das placas assumiram a função de identificação. $\mathrm{O}$ anonimato, neste caso, não se trata de um processo de silenciamento do sujeito produzido em um processo de alteridade, mas sim uma perspectiva cosmológica em que não há a individualidade. Numa reflexão sobre os processos de subjetivação, a partir dos saberes Yanomami, seria difícil conceber que o indivíduo se transforma em sujeito, quanto investido pela linguagem e pela história, já que para eles o social não se dicotomiza com o individual, nem a cultura com a natureza, como ficará mais claro na próxima análise.

\section{Poéticas visuais em Sonhos Yanomami: coetaneidade e fraturas}

As imagens da série fotográfica "Sonhos Yanomami" foram produzidas a partir de interferências técnicas da fotógrafa, que modificaram a espessura das fotografias. 


\section{PELOS OLHOS DE CLÁUDIA ANDUJAR: NECROPOLÍTICA E COETANEIDADE ENTRE OS YANOMAMI}

Para produzir uma imagem, ela reuniu dois ou mais fotogramas no ampliador, um aparelho usado no laboratório fotográfico para a obtenção de cópias em papel. Este processo deu origem a novos enunciados visuais, que por sua vez acionam uma nova atitude de seus interlocutores. Parte das fotografias desta série foi produzida ainda no início de sua carreira. Outras fizeram parte, inclusive, do projeto "Marcados", mas se reconfiguraram a partir da mudança na técnica e no conceito visual aplicado ao trabalho.

Alguns elementos técnicos que compõe uma imagem fotográfica, como a cor, por exemplo, já traz uma calibragem específica programada pelo fabricante da máquina fotográfica e isto interfere na imagem final. Seria o que podemos chamar de conceitos pré-codificados. Também devemos considerar os suportes pelos quais essa imagem será exposta: tela de computador, impressão em papel, porque também estas particularidades afetarão a resolução final da fotografia. Sobre o aspecto técnico Flusser (2011, p. 78) diz:

\footnotetext{
Transcodificam determinadas teorias (em primeiro lugar, teorias da ótica) em imagem. Ao fazê-lo magicizam tais teorias. Transformam seus conceitos em cenas... A fotografia em cores é mais abstrata que a fotografia em preto e branco. Mas as fotografias em cores escondem, para o ignorante em química, o grau de abstração que lhe deu origem. As brancas e pretas são, pois mais verdadeiras. E quanto mais fiéis se tornarem as cores das fotografias, mais estas serão mentirosas, escondendo ainda melhor a complexidade teórica que lhes deu origem (Exemplos: verde "Kodak" contra verde "Fuji") ... O que vale para as cores vale, igualmente, para todos os elementos da imagem. São todos eles, conceitos transcodificados que pretendem ser impressões automáticas do mundo lá fora.
}

Os enunciados visuais construídos em "Sonhos Yanomami” nos permite dizer, a partir de Foucault (2000, 2005a), que as condições de possibilidades históricas favoreceram essa construção e a modificação estrutural na imagem, que desloca nossa forma de ver, mantém a posição discursiva da obra de Andujar diante da política indigenista brasileira. As condições técnicas, sociais e subjetivas permitiram à fotógrafa criar novas visualidades sobre a sociedade Yanomami, a partir de sua interpretação do que é ser um Yanomami hoje. Seu lugar de enunciação é fraturado, no sentido que propõe D. Mignolo (2003), por se constituir nas fronteiras de duas cosmologias, a Yanomami e a ocidental. A fotógrafa se vale dos recursos tecnológicos ocidentais para a produção da imagem, mas mostra um ritual xamanístico.

Ao juntar imagens de épocas diferentes em uma única imagem, de forma singular, nestas narrativas visuais bastantes complexas faz emergir também as 
descontinuidades da história, no sentido que lhe atribui Michel Foucault (2005a), com tempos que nem iniciam e nem terminam, porque são espiralados, imbricados, inseparáveis. Os negativos fundidos não apenas fundem os tempos nas fronteiras da racionalidade ocidental, eles vão além. Como são imagens superpostas de paisagens e corpos indígenas, também nos permitem sentir a coetaneidade, o tempo Yanomami coexistindo com o olhar, a técnica e o tempo ocidentais.

Para este povo indígena, as estrelas, os rios, as plantas e os animais fazem parte de um grande círculo da vida, em que todos estão interligados. Diferente da perspectiva cosmológica ocidental, em que as pessoas estabelecem uma relação com a natureza, eles compreendem as pessoas como parte da natureza. As imagens da série "Sonhos Yanomami" versam sobre o ritual de passagem, pelo qual os corpos físicos desses indígenas se transformam em estados de energia e viram espíritos da floresta, os Xamãs e os Xaripë. As fotografais mostram uma "fusão" de corpos, sobrepostos, entre pedras, árvores e areia. Procuram traduzir o que eles acreditam ser a própria natureza, um encontro entre mulheres e homens e os espíritos dos antepassados.

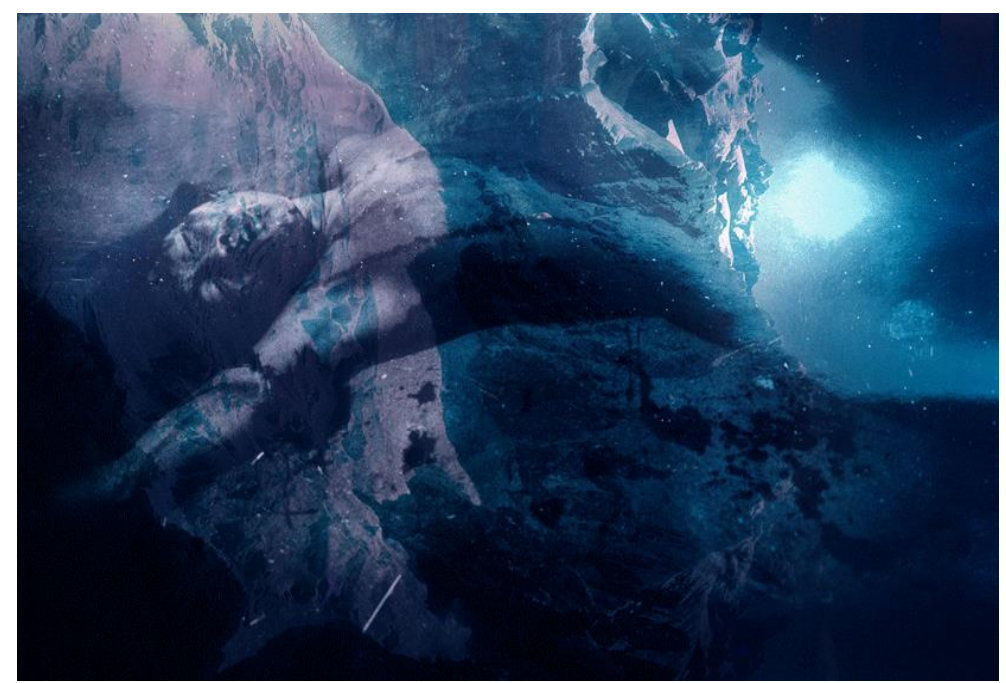

Figura 2. Da série "Sonhos Yanomami". Cláudia Andujar. Disponível em: <http:/ / www.frmaiorana.org.br/2010/2010.pdf>.

Na Figura 2, o azul é a cor predominante e à esquerda da fotografia, percebe-se um leve tom magenta, no alto, à direita nota-se um ponto forte de luz que surge no interior da imagem. O primeiro plano é ocupado, em diagonal, pelas formas de um corpo, do sexo masculino, caracterizado em detalhes, pelos cabelos curtos, partes do rosto, os olhos fechados, a boca cerrada, a cabeça virada para a esquerda. Dos membros inferiores e superiores, apenas uma parte do braço direito está visível na fotografia, um dos fatores que provoca certa desestabilidade ao olhar do interlocutor, uma vez que 
desconfigura o conceito que se estabeleceu historicamente sobre a constituição de um corpo humano.

Assim, esse corpo representado na imagem parece flutuar sobre nuvens e este aspecto lhe confere uma densidade espiritual. Trata-se de uma cena do ritual Xamânico Yanomami, que na cosmologia desta sociedade ocupa um lugar sagrado, um momento de reunião cósmica com a gênese do seu povo. A disposição deste corpo flutuante materializa a chegada dos espíritos para os Yanomami. Cláudia Andujar, com essa imagem deixa ver algumas singularidades deste ritual indígena e propõe outras formas de visibilidade para o sagrado, desassociada da cosmologia ocidental. Os espetros humanos das imagens de "Sonhos Yanomami" não dialogam com as imagens dos santos cultuados pela Igreja Católica.

Na próxima imagem (Figura 3), podemos ver, diante de um fundo preto, o detalhe de um rosto humano, que aparece em diagonal e preenche praticamente todo $o$ quadro. A fotografia apresenta vários pontos escuros e claros, que intensificam o contraste e a textura e evidenciam ranhuras e fissuras profundas. A imagem do rosto funde-se com a imagem de uma rocha e dessa fusão nasce uma narrativa poética sobre o urihi, a terra-floresta. Esta composição visibiliza um dos princípios fundamentais da cosmologia Yanomami, pois dissolve os limites entre as pessoas e os elementos da natureza.

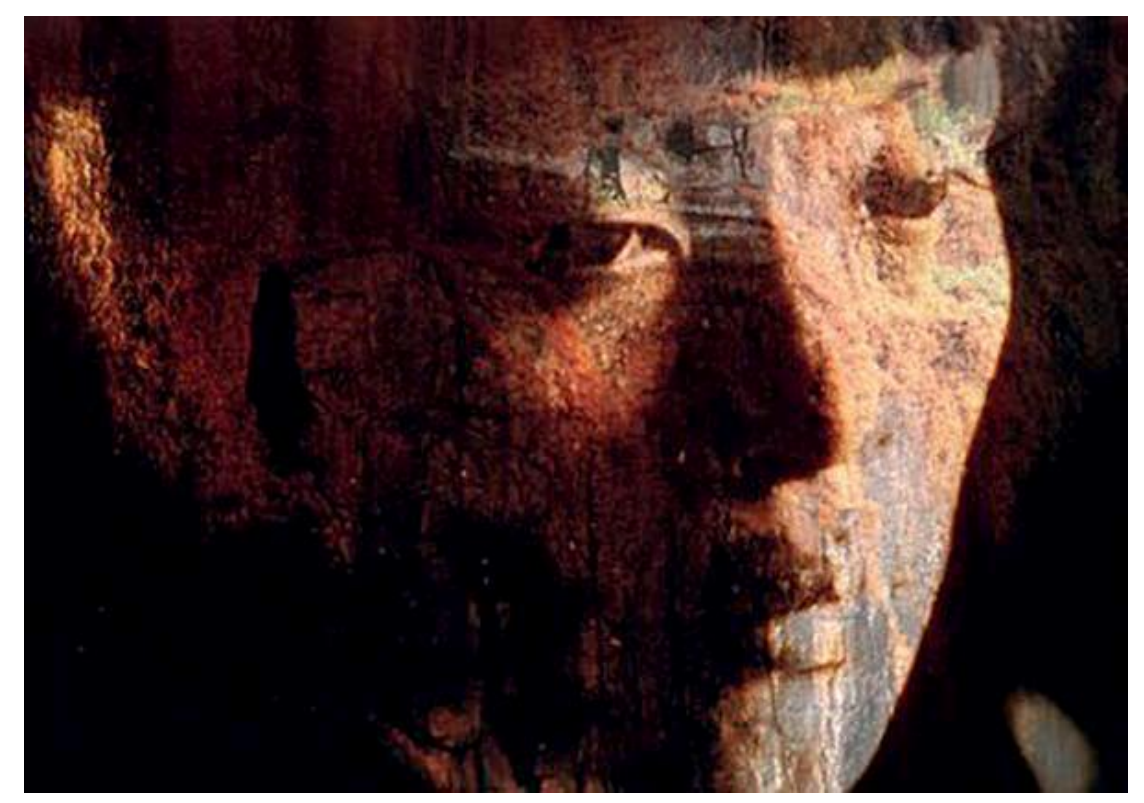

Figura 3. Hélio para os brancos. Foto: Cláudia Andujar. Disponível em: <http://www.frmaiorana.org.br/2010/2010.pdf>. 
O conjunto de efeitos visuais desta imagem suscita um clima de silêncio e produz uma sensação de tranquilidade diante da existência, perceptíveis e reforçados pela profundidade do olhar transversal e longínquo do indígena. Se fosse a imagem de uma escultura pré-colombiana, podíamos inscrevê-la num pretérito perfeito, concluído, mas como é a fotografia de um Yanomami, que vive no Brasil, nos dias de hoje, ela também desassossega nosso olhar. Embora pareça alheio à cena, o olhar de Hélio deixa ver uma relação de intimidade com a fotógrafa. Dubois (2010) nos diz que nos retratos o olhar transborda para além da cena recortada. Nesta fotografia, este olhar captado por Andujar nos coloca diante da história do povo Yanomami, das relações que se estabelecem com o outro e consigo mesmo, a partir da natureza.

O rosto é um elemento bastante presente nos retratos, desde o surgimento da fotografia, até os modernos selfies (DUBOIS 2010). Ele pontua momentos na história quando o retrato fotográfico passou a ser usado como documento, como objetos de recordação entre as pessoas. Nas duas séries, tanto em "Marcados" como em "Sonhos Yanomami", em perspectivas diferentes, o rosto traduz quem são os Yanomami dentro da sua tradição e no processo de contato com o não indígena.

A verticalização da experiência de Cláudia Andujar com os Yanomami lhe permitiu conhecer a genealogia e os processos culturais deste povo. A fotógrafa mergulhou no universo mítico dessa sociedade e procurou traduzir como eles mantêm contato com seus ancestrais, através dos rituais Xamânicos. Andujar traz para série "Sonhos Yanomami" uma interpretação visual dessa transcendência, vital para eles. A próxima fotografia apresenta outra cena do ritual xamanístico e um de seus principais sujeitos, o Guerreiro de Toototobi.

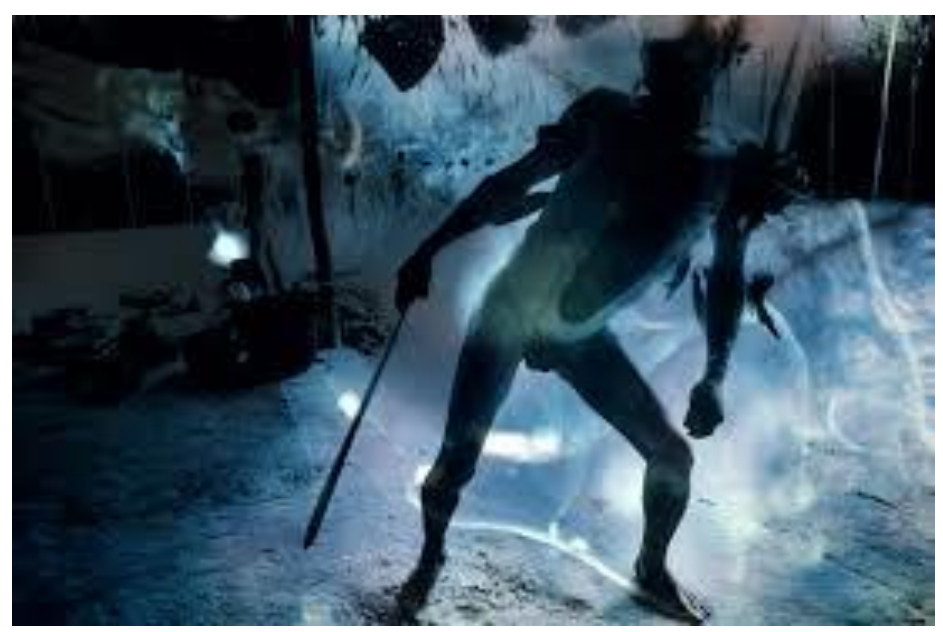

Figura 4. Guerreiro de Toototobi, da série: "Sonhos Yanomami". Foto: Cláudia Andujar. Disponível em: <http://www.frmaiorana.org.br/2010/2010.pdf>. 
Segundo Kopenawa Yanomami (2005, p. 89):

\begin{abstract}
Quando se toma pela primeira vez o pó da árvore yãkãanahi os espíritos xaripë começam chegar até você. Primeiro ouvem-se de longe seus cantos de alegria, tênues como zumbidos de mosquitos. Depois, quando olhos estão morrendo, começam-se ver luzes cintilantes que tremem nas alturas, vindas de todas as direções do céu. Aos poucos os espíritos se revelam, avançando e recuando com passos de dança muito lentos. Eles são minúsculos e pintados de cores brilhantes. Suas cabeças são cobertas de plumas brancas de gavião e suas braçadeiras cheias de rabos de arara e de papagaio. Dançam em círculo sem pressa. Mas, de repente, armados com grandes "espadas", partem ao meio sua coluna vertebral. Cortam sua cabeça e sua língua. Sente-se então uma dor intensa e você desmaia. Seu envelope corporal fica no chão, mas os xaripë voam para longe, levando as partes do seu corpo imaterial. Deitam-nas em seus espelhos, nas costas do céu, e pintam-nas com urucum. Raspam sua língua e a cobrem de plumas brancas. Mais tarde recompõem seu corpo, mas ao contrário: juntam a cabeça no lugar do traseiro e as pernas no lugar dos braços. Uma vez virado do avesso, você pode responder aos espíritos e imitar seus cantos, você pode ser um xamã.
\end{abstract}

"Sonhos Yanomami" nos apresenta um universo constituído pelo visível e o invisível, atravessado pelas memórias pessoais, de Cláudia Andujar, dos sujeitos representados nas imagens e as memórias dos possíveis interlocutores dessa produção. As fotografias se confundem entre visualidades poéticas e a foto documentação. Cabe ao interlocutor negociar suas interpretações, quer sejam os próprios Yanomami, outros indígenas ou não indígenas e projetar suas subjetividades neste universo plural das imagens, inscritas em uma fronteira cultural que não delineia um único espaço ou um único tempo. A série transcende o registro literal físico da paisagem e do humano da Amazônia.

\title{
Considerações finais
}

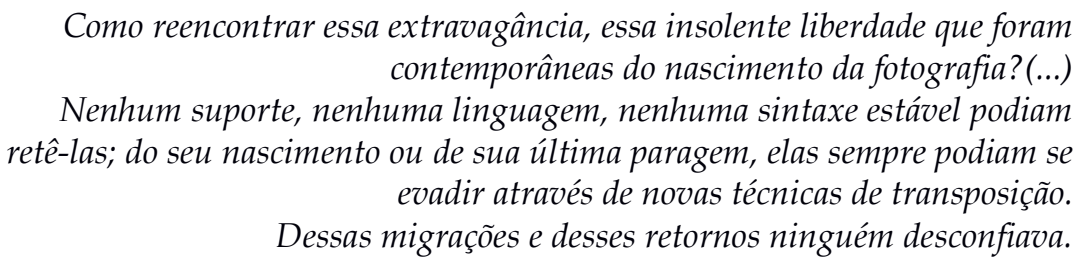

Michel Foucault

As séries de Cláudia Andujar nos convidam a retomar as discussões sobre fotografia e realidade. Embora possamos situá-las numa realidade específica, a partir do 
olhar de um sujeito, que singulariza a imagem, ao recortar uma cena e não outra, o caráter fraturado do seu lugar de enunciação e a coetaneidade presente nas imagens não cabem numa perspectiva unidimensional de realidade. Neste sentido, talvez fosse mais coerente pensar que elas extrapolam e pluralizam a realidade. Como propõe Roland Barthes (2009, p. 14): “Seja o que for o que ela dê a ver e qualquer que seja a sua maneira, uma foto é sempre invisível: não é ela que nós vemos".

A partir da experiência de Cláudia Andujar, podemos compreender um pouco melhor essa relação política de realidade/fotografia na perspectiva dos Yanomami e ela, então nos coloca diante de uma perspectiva epistemológica que considera mais de uma cultura. A imagem tem diferentes sentidos histórico-culturais. Muitas vezes entendemos a dinâmica da vida como se a nossa cosmologia fosse universal e todas as pessoas vivessem a partir de uma lógica única.

Segundo Andujar $(1998,2011)$, para os Yanomami a fotografia é recebida de diferentes formas. Para uma parte deles os registros eram indiferentes e não se reconheciam nas fotos. Outros, no entanto, gostavam bastante de serem vistos nas imagens e queriam ser fotografados. Há uma particularidade desta cultura em relação à imagem, que afetava a todos, a preocupação com a morte. Todas as suas fotografias devem ser destruídas, para que suas almas não fiquem aprisionadas. Tradicionalmente, entre os Yanomami, tudo que pertenceu ao indígena que recebeu o ritual de passagem deve ser destruído. Tudo que o ligue à vida deve desaparecer, até a cremação do seu corpo, porque é o momento da liberação de sua alma.

Nós, moradores das grandes cidades, estabelecemos formas bem diferentes de relação com as fotografias. Nos selfies[3] das redes sociais, nos antigos álbuns empoeirados guardados nos armários, nas luxuosas encadernações de capa dura dos catálogos de fotógrafos famosos, nas galerias e museus, nas páginas resistentes das revistas e dos jornais impressos, inventamos imagens perpetuadas num tempo contínuo, monocultural.

Cláudia Andujar encontrou uma alternativa singular para interagir com os Yanomami e dissolveu os limites desta instituída temporalidade única, oficial. Suas fotografias nos desafiam a pensar sobre o nosso próprio tempo. Viveríamos todos nós, este imenso e heterogêneo conjunto de sociedade genericamente arroladas na rubrica de ocidentais, dentro de um tempo contínuo dividido em antes e depois de Cristo?

Para Fabian (2013), preocupado com os tempos da antropologia, administrados nas fronteiras culturais, não se chega a um processo de interação mais significativo sem 
se reconhecerem as diferentes temporalidades, para negociar um meio do caminho. Talvez não devêssemos restringir esta preocupação mesmo para quem vive supostamente dentro do mesmo universo cultural.

\section{Notas de rodapé}

[1] O Etnômio "Yanomami" foi criado pelos antropólogos a partir das expressões yanamae thëp" ou yanãmami thëpë que significam "seres humanos". (ALBRTE, 2005).

[2] “La ocupación colonial de la modernidad tardía es un encadenamiento de poderes múltiples: disciplinar, «biopolftico»y «necropolftico». La combinación de los tres permite al poder colonial una absoluta dominación sobre los habitantes del território conquistado.".

[3] Atuais retratos populares que circulam na internet, (grifo nosso).

\section{Referências}

ALBERT, Bruce in: ANDUJAR, Cláudia. Yanomami. Curitiba: Gráfica e Editora Posigraf, 2005.

ANDUJAR, Cláudia. Marcados. São Paulo: Cosac Naify, 2009.

Yanomami. Curitiba: Gráfica e Editora Posigraf, 2005.

BAETENS, Jan. A volta do tempo na fotografia moderna In SAMAIN, Etienne. $O$ Fotográfico. São Paulo: Editora Hucitec/Editora Senac, 2005.

BARTHES, Roland. A câmara clara: Nota sobre a fotografia. Lisboa Edições 70, 2009.

COURTINE, J.-J. Discursos e imagens para uma arqueologia do imaginário. In: SARGENTINI, V.; PIOVEZANI, C.; CURCINO, L. (Ed.). Discurso semiologia e história. São Carlos: Claraluz, 2011, p. 145-162.

DUBOIS, Philippe. O ato fotográfico e outros ensaios. Campinas: Papirus, 2010.

ENTLER, Ronaldo. A fotografia e as representações do tempo. Revista Galáxia, São Paulo, 2007.

ENTREVISTA. Cláudia Andujar. Provocações. TV Cultura de São Paulo. Disponível em: $<$ http:/ / tvcultura.cmais.com.br/provocacoes/antonio-abujamra-entrevista-afotografa-Cláudia-andujar-bloco-02-> Acesso em: 01 out. 2016.

FABIAN, Johannes. O Tempo e o Outro: como a antropologia estabelece seu objeto. Petrópolis: Vozes, 2013. 
FLUSSER, Vilém. Filosofia da caixa preta: Ensaios para uma futura fotografia. São Paulo: Annablume, 2011.

FOUCAULT, Michel. A Governamentalidade In. Ditos e Escritos IV: Estratégia, PoderSaber. Rio de Janeiro, Editora Forense Universitária, 2012.

Arqueologia do saber. Rio de Janeiro: Forense Universitária, 2005a.

. A Microfísica do Poder. Rio de Janeiro: Graal, 2007.

A ordem do discurso: aula inaugural no Collège de France, pronunciada em 2 de dezembro de 1970. São Paulo: Edições Loyola, 2000.

Estética: literatura e pintura, música e cinema. Ditos e escritos III. Rio de Janeiro: Forense Universitária, 2006, p 346 - 355.

Vigiar e Punir. Petrópolis: Vozes, 2005b.

HILÁRIO, Leomir Cardoso. Da biopolítica à necropolítica: variações foucaultianas na periferia do capitalismo. Revista Sapere Aude, Belo Horizonte, 2016.

MAIORANA, Roberta. 29 Arte Pará. Belém Pará: Gráfica e Editora Halley, 2011. MBEMBE, Aquile. Necropolítica. Madrid: Melusina, 2006.

MIGNOLO, Walter. Histórias Locais / Projetos Globais: Colonialidade, Saberes Subalternos e Pensamento Liminar. Belo Horizonte: Editora UFMG, 2003.

NOVAES, Sylvia Cauby. O uso da imagem na Antropologia. In: SAMAIN, Etienne. O Fotográfico. São Paulo: Editora Hucitec/Editora Senac, 2005.

PERSICHETTI, Simonetta. Imagens da fotografia brasileira 2. São Paulo: Estação liberdade/ Senac SP, 2000.

REINHARDT, Bruno. Poder, história e coetaneidade: os lugares do colonialismo na antropologia sobre a África. Revista da USP, São Paulo, 2014.

TACCA, Fernando de. O índio na fotografia brasileira: incursões sobre a imagem e o meio. História, Ciências, Saúde, Manguinhos, Rio de Janeiro, v.18, n.1, 2011.

YANOMAMI, K. Entrevista In ANDUJAR, Cláudia. Yanomami. Curitiba: Gráfica e Editora Posigraf, 1998.

Recebido em 16/12/2016

Aceito em 05/02/2017. 